\title{
Multidisciplinary Optimisation Framework for Minimum Rotorcraft Fuel and Air Pollutants at Mission Level
}

\author{
Carlos Linares, Craig P. Lawson, Howard Smith \\ School of Engineering, Cranfield University, United Kingdom
}

\begin{abstract}
Helicopters play a unique role in modern aviation providing a varied range of benefits to society and satisfying the need for fast mobility. However, environmental concerns associated with the operation of rotorcraft have increased due to envisaged growth of helicopter operations. New rotorcraft designs, innovative aero engines and all-electrical systems, which may take decades to be in service, are being developed in order to diminish rotorcraft footprint on environment. However, since there is a large number of polluting rotorcraft that are in use and will only gradually be replaced, in the nearterm, improvements to minimise air quality degradation may also be possible from better use of existing rotorcraft by focusing on mission profile management. A multidisciplinary framework, intended to generate outputs for estimating rotorcraft block fuel burn and emissions, was developed. Outcomes generated with this tool were, subsequently, the basis to carry out a parametric study for assessment of light single-engine rotorcraft environmental impact, in terms of fuel burn and emissions. Single and multi-objective optimisation for minimum fuel consumption and air pollutant emissions was part of this research as well.
\end{abstract}

Case studies were carried out varying flight parameters at every segment of a baseline mission profile. Single and multi-objective optimisation proved that favourable reductions in fuel burn of about $2 \%$ may be attainable at the expense of a slight increase in $\mathrm{NO}_{x}$ emissions during the entire mission. If reductions of more than $3 \%$ in block fuel burn are to be achievable in the short term for a single helicopter, savings for air transport companies are expected to be significant if mission profile management is considered for a whole fleet of helicopters.

\section{Nomenclature}

\begin{tabular}{|c|c|c|}
\hline$K_{p c}$ & Climb Efficiency Factor & \\
\hline$P_{a v}$ & Power Available & {$[\mathrm{kW}]$} \\
\hline$P_{\text {level }}$ & Power Required in Level Forward Flight & {$[\mathrm{kW}]$} \\
\hline$W_{f}$ & Fuel Flow & {$[\mathrm{kg} / \mathrm{s}]$} \\
\hline AoA & Angle of Attack & \\
\hline CAMRAD & $\begin{array}{l}\text { Comprehensive Analytical Model of Rotorcraft } \\
\text { Aerodynamics and Dynamics }\end{array}$ & \\
\hline $\mathrm{CO}$ & Carbon Monoxide & \\
\hline DOE & Design of Experiment & \\
\hline ECS & Environmental Control System & \\
\hline EI & Emissions Index & \\
\hline $\begin{array}{l}\text { EMPRESS } \\
\text { FOCA }\end{array}$ & $\begin{array}{l}\text { Energy Method for Power Required Estimates } \\
\text { Federal Office of Civil Aviation }\end{array}$ & \\
\hline$h$ & Altitude & \\
\hline $\mathrm{H}_{2} \mathrm{O}$ & Water Vapour & \\
\hline HESCOMP & $\begin{array}{l}\text { The Helicopter Sizing and Performance Computer } \\
\text { Program }\end{array}$ & \\
\hline IGE & In Ground Effect & \\
\hline ISA & International Standard Atmosphere & \\
\hline MTOW & Maximum Takeoff Weight & \\
\hline NDARC & NASA Design and Analysis of Rotorcraft & \\
\hline NO & Nitric Oxide & \\
\hline $\mathrm{NO}_{2}$ & Nitric Dioxide & \\
\hline $\mathrm{NO}_{x}$ & Oxides of Nitrogen & \\
\hline
\end{tabular}




$\begin{array}{llr}\text { OGE } & \text { Out of Ground Effect } & \text { [g] } \\ \text { PM } & \text { Particulate Matter } & \\ \text { RMEM } & \text { Rotorcraft Mission Energy Management Model } & {[\mathrm{g} / \mathrm{kN} \text { s] }} \\ \text { SFC } & \text { Specific Fuel Consumption } & {[\mathrm{g}]} \\ \text { ToC } & \text { Top of Climb } & {[\mathrm{kW}]} \\ \text { UHC } & \text { Unburnt Hydrocarbons } & {[\mathrm{kt}]} \\ S H P & \text { Shaft Horse Power } & {[\mathrm{min}]} \\ V & \text { Forward Speed } & {[\mathrm{m}]} \\ k & \text { Induced Power Correction Factor } & \\ t & \text { Time } & \\ z & \text { Skid Height } & \\ \delta & \text { Pressure Ratio } & {\left[\mathrm{kg} / \mathrm{m}^{3}\right]} \\ \theta & \text { Temperature Ratio }\end{array}$

\section{Introduction}

The air transport industry is foreseen to continue growing during the next decades leading to environmental implications in terms of noise and air quality. Consequently, this demand must be addressed in an appropriate manner if aviation is to meet passenger's needs whilst preserving the environment, otherwise the environmental effects might become a limitation to growth in due course.

Currently, climate change and stratospheric ozone depletion have emerged as the main environmental issues ascribed to the air transport industry. Changes in weather patterns (i.e. precipitation, temperatures, etc.) and increase in ultraviolet radiation (e.g. UVB) are pointed to as some of the main consequences of these two environmental issues. Stratospheric ozone depletion is mostly related to supersonic flight, which is not the case of helicopters; on the other hand, understanding the concept of climate change may provide a better insight into what could be achieved in terms of greenhouse emissions.

Methodologies including optimisation algorithms have been developed at Cranfield University in order to determine ideal trajectories for particular operational and environmental limitations ${ }^{(1)}$. Even though emissions such as particulate matter and unburnt hydrocarbons, as well as losses due to helicopter secondary power systems, are not considered in this study, there seems to be a potential for reduction of $\mathrm{NO}_{x}$ emissions and fuel burn by means of mission analysis.

Slater and Ezberger ${ }^{(2)}$ also developed an algorithm to define optimal flight paths for helicopters, focusing only on minimum fuel burn and minimum operating costs. This study suggests the optimisation of flight paths is attractive as a means of reducing fuel consumption and, therefore, the costs of operating helicopters. However, the integration of takeoff and landing phases is required. Although this study provides outcomes in terms of the relation of cost and benefit as well as fuel savings, it does not report environmental benefits.

Additional models for simulation of rotorcraft performance and sizing such as NDARC (NASA Design and Analysis of Rotorcraft), CAMRAD II (Comprehensive Analytical Model of Rotorcraft Aerodynamics and Dynamics), HESCOMP (The Helicopter Sizing and Performance Computer Program) and EMPRESS (Energy Method for Power Required Estimates) have been developed during the last decades, but these tools have been created mainly for helicopter design purposes ${ }^{(3 ; 4)}$.

Alternative models have also been developed to predict flight performance of existing helicopters in order to assess their operating limits for upgrading programs ${ }^{(5)}$. However, assessment of helicopter environmental footprint at mission level cannot be carried out with these tools as their cost is translated into a restriction to achieve the objectives of this research project. 
This research is aimed at estimating fuel burn and emissions, providing a preliminary overview of the environmental impact of the operation of conventional helicopter configurations at mission level. In addition, this study is intended to develop a multidisciplinary optimisation framework which can then be used to assess the environmental footprint of helicopters, in terms of fuel and emissions, under various flight conditions during a given mission profile. A parameter study is, therefore, carried out in order to explore the design space (i.e. mission profile) followed by a single and multi-objective optimisation, leading to the determination of appropriate flight parameters to operate helicopters for minimum fuel burn and emissions (i.e. due to air pollution).

A number of case studies, based on a conventional mission profile, are executed by means of a multidisciplinary approach. Consequently, a computational tool for the prediction of helicopter mission performance is developed to be integrated into the above-mentioned multidisciplinary framework, which is intended to generate outputs for estimating the amount of fuel burn and emissions produced by engines of conventional helicopters at mission level. Results derived from this assessment may provide an overview on what is possible in terms of reduction of air pollutants and fuel by means of mission profile management.

The multidisciplinary optimisation framework allows the interaction of key aerospace disciplines. The governing equations of some models, created with Simulink and contained within the assessment framework, are represented in low fidelity. This framework has the capability to incorporate additional models required for future development and expansion.

This research is restricted to light single-engine helicopters and a particular role (i.e. corporate transport role) is chosen based on the applicability of this helicopter category. A Bell 206L-4 was selected to carry out the case studies as its size and performance characteristics meet the requirements for a passenger transport role.

In the real world there is not a defined baseline mission profile for helicopters; however, because this research study focuses on the multidisciplinary framework for optimisation of helicopter missions, a one-way baseline mission was required to evidence the capabilities of the framework. As a result, a baseline mission profile, which is to be optimised, has been defined based on a combination of four typical segments, found in most helicopter missions. A standard scenario with particular flight conditions was defined using parameters provided by experienced pilots, as well as basic performance data from the manufacturer, as discussed in section 2.6.

\section{Multidisciplinary Optimisation Framework.}

A multidisciplinary framework is proposed for the assessment of the environmental impact of conventional helicopter configurations (Fig. 1). Each discipline contained within the framework applies its own governing equations to deliver the outputs required for assessing the environmental impact, in terms of fuel consumption, caused by light single-engine helicopters at mission level. These outcomes provide an overview of the potential that helicopter mission profile management has on reducing air pollutant emissions.

The multidisciplinary optimisation framework contains four independent models; namely, rotorcraft mission energy management model (RMEM), helicopter mission performance model, engine performance model and emissions model. In addition to these models, a Simulink $\circledast$ optimiser can be coupled to the multidisciplinary framework as optimisation is to be carried out for particular objectives such as minimum fuel burn or minimum $\mathrm{NO}_{x}$ emissions.

The helicopter mission performance model, the rotorcraft mission energy management model and the emissions model were developed with Simulink $\AA$, whereas the engine performance calculations were carried out in Turbomatch, which is a gas turbine software code developed at Cranfield University ${ }^{(6)}$. It is worth noting that this model-based tool is suitable for further development and expansion since 
incorporation of additional models (e.g. aerodynamics, operating costs, noise, etc.) is possible if any improvements are to be made.

\subsection{Helicopter Mission Performance Model}

The helicopter mission performance model is composed of three key models or subroutines: the hovering flight model, the forward flight model and the forward climb model. Each model represents a particular segment of a mission in which power and fuel requirements are calculated. These three fundamental models are complemented with an auxiliary model that computes physical properties of Standard Atmosphere such as density, pressure, temperature and speed of sound at a given altitude.

From general equations of momentum, energy conservation and fluid mass, the hovering flight subroutine calculates helicopter power requirements, which are then translated into fuel mass. Nonideal effects such as induced tip loss, non-uniform inflow, finite number of blades, and so on, are considered using an induced power factor for the rotor, $k$, or so called induced power correction factor, whose typical value is estimated to be around $1.15^{(7)}$. Other power losses such as blade profile drag and three-dimensional flow at the blade tip must be added to the induced power equation ${ }^{(8)}$.

In the case of the forward flight model, performance estimation for cruise level flight conditions is accomplished by calculating the power and fuel requirements at given flight conditions. As in hovering flight, momentum theory is also applied; however, in flight at high speeds, the downwash field of a rotor is treated as in the case of a fixed-wing aircraft because the rotational speed of a rotor disc becomes smaller compared to the horizontal speed of the helicopter ${ }^{(9)}$. As a result, momentum theory can be complemented by incorporating changes of rotor aerodynamics through the rotor disc based on certain assumptions (e.g. considering the rotor disc as a fixed-wing $)^{(7)}$. Note that in forward flight, the flow through the rotor disc is not axisymmetric, as it is in hovering flight conditions, since the rotor disc must be tilted forward at a given AoA (i.e. relative to the forthcoming flow).

Under these conditions, the induced inflow ratio $\lambda$, which is a parameter required to calculate induced power requirements, may be obtained from trim equations. Though, Bramwell et $a{ }^{(10)}$ suggest that calculation of the trim parameters is not essential if only helicopter performance is to be assessed. From a realistic point of view, the tilt angle never equals zero when a helicopter is moving forward. So, for a non-axial flow, a numerical approach, such as a fixed-point iteration or a Newton-Raphson iterative method, can be useful when computing the value of the rotor inflow ratio for a range of speeds ${ }^{(3)}$. In this particular model, the Newton-Raphson method was used to solve for $\lambda^{(11)}$.

In addition to the forward and hovering flight subroutines and considering the architecture of these tools, climb power is predicted based on the excess of shaft power available $P_{a v}$ from the engine over that required for level forward flight $P_{\text {level }}$. It is worth noting that during climb, the mean blade drag coefficient, which affects helicopter rotor profile power, changes with altitude; therefore, for this particular model, the profile power is assumed to be constant, still providing good estimations of power and fuel requirements.

A climb efficiency factor $k_{p c}$, which can be derived from flight test data or wind tunnel tests, must be added. As stated in Stepniewski et $a^{(12)}$, this factor is found to be $0.8<k_{p c} \leq 0.9$ for single-rotor helicopters, but an average value of $k_{p c}=0.85$ can be used for preliminary purposes, representing losses due to other factors such as fuselage lift and drag, tail rotor power, which also changes during climb, transmission efficiency and induced power. Increased drag due to higher angles of attack of the fuselage, higher profile power as a result of blade pitch increase and changes in tail rotor power required during climb may cause power requirements to be underpredicted at low speed climb. 


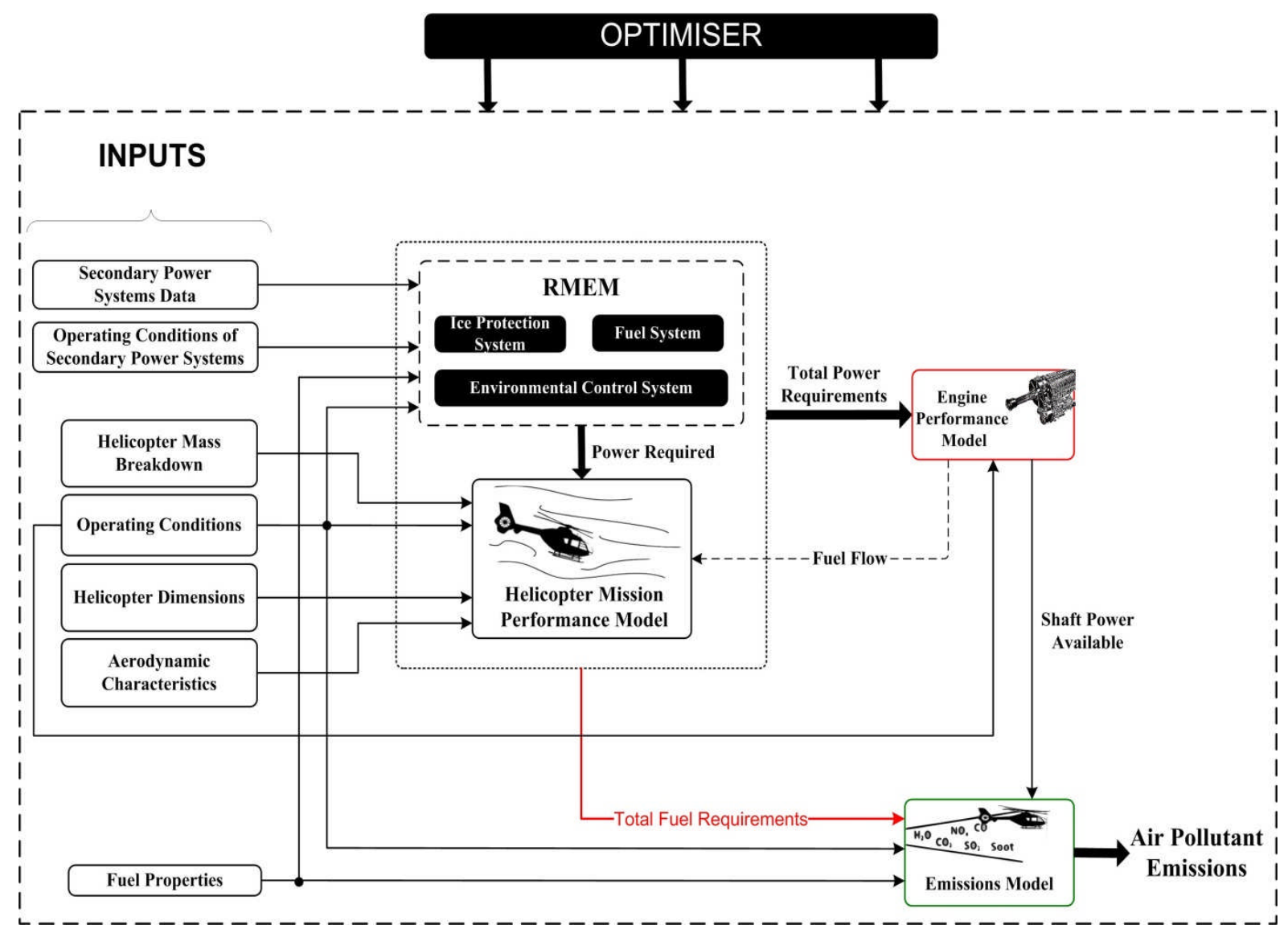

Fig. 1. Multidisciplinary Optimisation Framework

An additional model, which depends mainly on engine performance inputs, calculates fuel requirements on ground (i.e. taxi, warmup and shutdown) and can also be linked to other segments of the mission as required.

Supplementary models to estimate helicopter capabilities such as maximum rate of climb, time to climb and distance to climb are also incorporated as they are necessary to determine fuel requirements during climb conditions. The models can be linked in such a manner that helicopter mission performance can be predicted for a corporate mission role in terms of fuel consumption. This steady-state model provides good results in terms of fuel prediction ${ }^{(13)}$; however, thanks to the capabilities of Simulink to simulate dynamic systems, the helicopter mission performance tool can be developed further using trim equations for prediction of green trajectories in $4 \mathrm{D}$, where the helicopter attitude and changes of speed with respect to time can be considered.

\subsection{Emissions Model}

Six turboshaft engine products are considered within this model, which is based on a parameter named emissions index (EI). This factor is the ratio of produced grams of a specific pollutant to kilograms of fuel burnt and may be estimated by means of four approaches: detailed computational models, simplified physics-based models, semi-empirical models and empirical models. Allaire (14) $^{(14)}$ provides a detailed and clear description of these methods.

The present emissions model contained within the multidisciplinary optimisation framework uses empirical and stoichiometric expressions in order to calculate Els of the main products of turboshaft engines and relies entirely on the resulting fuel flow and power requirements from the helicopter mission performance model. Helicopter emissions are not easily assessed since turboshaft engine 
emissions data are usually not available in the public domain and there is no generally recognised approach on how to estimate helicopter emissions. For this reason, in 2008, the Federal Office of Civil Aviation (FOCA) launched a project named Helicopter Engines (HELEN), intended to fill gaps of knowledge regarding the determination of helicopter emissions.

Throughout the HELEN project, an empirical approach was assumed and measurements of turboshaft engine emissions were made during tests carried out after overhaul. As a result, mathematical functions for helicopter engine emission factors were proposed on the basis of these measurements. Further refinements to the emissions model are suggested by means of detailed computational models or a physics-based approach, which are more accurate for estimation of turboshaft engine emissions.

\subsubsection{Oxides of Nitrogen (NOX), Unburnt Hydrocarbons (UHC), Carbon Monoxide (CO) and Particle Matters (PM)}

A linear regression approach from the Federal Office of Civil Aviation (FOCA $)^{(15)}$, with given measurable outcomes (i.e. Els), is applied in order to calculate simple functions that describe the relation between parameters (e.g. shaft horsepower) and results. The key purpose of the FOCA functions is to get fuel flow values and the emissions factors for the following pollutants: $\mathrm{NO}_{\mathrm{x}}, \mathrm{UHC}$, $\mathrm{CO}$, and PM. However, within this particular framework, fuel requirements are calculated by the helicopter mission performance model, which depends on the engine performance model outcome; therefore, FOCA correlations for calculation of fuel requirements are not required in this research. $F{ } A^{(15)}$ states that "due to a substantial variability of real measured emissions data between different engine types, the suggested general approximation functions for emissions may still lead to an error of a factor of two or more for a specific engine. The suggested formulas are representing the current state of knowledge". FOCA also suggests that if additional refinements are to be made, additional data would be essential.

\subsubsection{Carbon Dioxide $\left(\mathrm{CO}_{2}\right)$ and Water Vapour $\left(\mathrm{H}_{2} \mathrm{O}\right)$ Emissions}

In addition to the engine products cited in the previous section, a stoichiometric approach is chosen to predict the concentration of carbon dioxide and water vapour emissions since they constitute the result of complete combustion. Both $\mathrm{CO}_{2}$ and $\mathrm{H}_{2} \mathrm{O}$ are influenced only by fuel consumption, and are independent of engine performance parameters and combustor geometry ${ }^{(16)}$. Els for these species are a function of the amount of carbon, hydrogen and oxygen contained within the fuel; thus, fuel flow is considered as the key driver of total $\mathrm{CO}_{2}$ and $\mathrm{H}_{2} \mathrm{O}$ emissions produced for a given fuel ${ }^{(17)}$. Els for $\mathrm{CO}_{2}$ and $\mathrm{H}_{2} \mathrm{O}$ are calculated based on a stoichiometric analysis in which the typical atomic weight of the elements involved in the reaction is considered. For this particular case, the atomic weights of carbon $\left(W_{C}\right)$, oxygen $\left(W_{O}\right)$ and hydrogen $\left(W_{H}\right)$ are taken into account in order to estimate the Els for both products. . For civil aviation fuels, Els for $\mathrm{CO}_{2}$ and $\mathrm{H}_{2} \mathrm{O}$ are found to be $3160[\mathrm{~g} / \mathrm{kg}]$ and 1230 $[\mathrm{g} / \mathrm{kg}]$, respectively. It is worth clarifying that relatively small variations of these Els are found in aviation fuel ${ }^{(16)}$.

\subsection{Rotorcraft Mission Energy Management Model (RMEM)}

The RMEM is a tool created at conceptual level in order to predict the power requirements of secondary power systems of a helicopter during a complete mission profile or segment. Within the scope of this research project, the airframe systems that compose the RMEM are: ice protection system, fuel system and environmental control system. Fellow members of the Clean Sky Joint Technology Initiative (JTI) at Cranfield University developed and validated each model independently.

Since the power requirements of most of the airframe systems rely on atmospheric conditions, the RMEM holds an extra Standard Atmosphere model to calculate air properties at any given altitude. Additionally, the secondary power systems have an impact on helicopter mission performance; 
consequently, power requirements of each individual system must be added to the helicopter power required if this impact is to be taken into account.

\subsubsection{Electro-Thermal Ice Protection System}

This Simulink model is based on the Messinger control volume method ${ }^{(18)}$ for computing the ice growth over a given surface in severe icing conditions. Anti-ice protection for small helicopters is usually provided for engine intakes and pitot-heating equipment so that the helicopter weight is not penalised. The Messinger approach suggests the heating surface is divided into control volumes in which a mass and energy balance is executed to predict the fraction of the balance temperature and the non-freezing water.

The mass balance analysis was carried out to compute the rate of water catch and evaporation in each control volume. Heat transfer coefficients and heat flux values were obtained by means of energy balance analysis. System power requirements (i.e. outputs) are then driven by the governing equations related to conservation of mass and energy and other flight parameters (i.e. inputs) associated to the operational conditions of the helicopter.

\subsubsection{Fuel System}

A helicopter fuel system consists of two major subsystems; namely, the fuel supply system and the engine fuel control system. The present fuel system model focuses only on the fuel supply system but it is expected to include an engine fuel control system in the future. In the fuel supply system, the component that requires large amounts of power for the system to work is the fuel pump. As a result, the fuel system model, which calculates power requirements for light single-engine helicopters equipped with a scavenge pump to suck up fuel from the system tanks, is rather simple since power requirements depend only on fuel pump characteristics, fuel tank dimensions and characteristics of the fuel that runs through the system. Power requirements during the whole mission are always the same because the system must ensure fuel is provided to the engine without flow interruption ${ }^{(8)}$.

\subsubsection{Environmental Control System}

The Environmental Control System (ECS) model computes the amount of energy consumed in terms of electrical power, pneumatic power and fuel flow under certain configuration and operational conditions for a fixed operational point. Vega ${ }^{(19)}$ developed the ECS model based on a review of the most common configurations mounted on more than 20 helicopters; this review concluded that the installation of the ECS is optional for civil helicopters. The survey also showed that for heating purposes, a combustion heater can be used whereas cooling of the cabin is attained by means of an air cycle machine. In the case of civil aviation, the selection of the ECS arrangement is driven by the customer requirements and depends on what kind of role the helicopter is performing. Vega ${ }^{(19)}$ provides a detailed description of the ECS model; several cases, for heating and cooling conditions, were executed in order to confirm the tool works properly.

\subsection{Turboshaft Engine Performance Model}

For mission performance calculations such as range and endurance, knowledge of the engine fuel consumption is necessary. In general, fuel consumption is estimated from power required curves, which are unique for a specific type of engine. In the case where no computational tool is available for calculation of engine performance data, an initial estimate can be made assuming that the specific fuel consumption (SFC) is not governed by the power output of the engine. This is a valid assumption because, usually, helicopters operate close to their maximum rated power ${ }^{(7)}$.

This research, however, incorporates engine performance data into the performance analysis of the helicopter using the Turbomatch engine performance tool developed at Cranfield University. 
Particular outputs from the engine performance model are then required to calculate mission performance of a helicopter (i.e. using the mission performance tool). Inputs required to execute a complete mission profile are fuel flow and power available for particular off-design conditions.

The characteristics of turbine engines are such that the relationship of power $(S H P)$ and fuel flow $\left(\dot{W}_{f}\right)$ results in a single curve that relates these parameters to sea level conditions (i.e. corrected fuel flow and corrected shaft power) ${ }^{(20)}$. Before any equation is developed for determining a single curve that describes fuel consumption characteristics of a particular engine, corrected fuel flow and corrected shaft power for turboshaft engines must be calculated. Then, the fuel flow rate, which is nearly a linear function of power output, is defined in the generalised (i.e. referred or corrected) form given in equation (1).

$$
\frac{\dot{W}_{F}}{\delta \sqrt{\theta}}=\mathrm{N}_{E} \mathrm{~A}_{E}+\mathrm{B}_{E}\left(\frac{P}{\delta \sqrt{\theta}}\right)
$$

Where: $\mathrm{A}_{E}$ and $\mathrm{B}_{E}$ are coefficients of a particular engine. For a multiengine helicopter, this function may be written in terms of the number of engines, i.e. $\mathrm{N}_{E}$. Coefficients $\mathrm{A}_{E}$ and $\mathrm{B}_{E}$ were calculated using Turbomatch results. Subsequently, this expression was modelled in Simulink in order to provide fuel consumption data to the helicopter performance model.

Hugon ${ }^{(21)}$ carried out the respective simulations in Turbomatch for an Allison turboshaft engine, model 250-C30R, which is the corresponding engine of the helicopter selected (Bell 206L-4) to execute the case study. Corrected Fuel flow results are used by the helicopter mission performance model and then related to the corresponding flight condition of the helicopter.

Linking of the engine performance model and the helicopter mission performance model is then accomplished by means of this generalised function (Equation (1) created from TURBOMATCH offdesign point results ${ }^{(21)}$. Also, lookup tables, which contain a collection of engine variables (i.e. engine power available) that depend on engine operating conditions, are considered to substitute a runtime computation with an array of values in order to save processing times significantly. However, development of an engine performance tool with Simulink for design-point and off-design point performance analysis would be favourable for further expansion of the multidisciplinary optimisation tool.

\subsection{Design of Experiment Technique (DOE)}

The results of a number of case studies, obtained with the multidisciplinary tool, are the basis of the use of a design of experiment technique (e.g. parameter study, full-factorial, central composite, etc.) that may provide a systematic approach to explore the design space for minimum air pollutant emissions. At first, a parameter study was conducted considering at least two factors or variables of interest, which are usually present in every segment of any mission profile. In addition to that, a range of levels or variations of each factor is considered according to the performance of the helicopter and its operating constraints (e.g. maximum speed, service ceiling or rate of climb). Likewise, the most attractive factors were considered for a full-factorial design of experiment as it may provide a wider outlook of the design space. So, every output was evaluated at every combination of values.

The next stage consisted in determining the region in the factors leading to an optimal solution (i.e. objectives). First, a single-objective optimisation was carried out for minimum block fuel burn and for minimum turboshaft engine products (i.e. those considered throughout this document). The objectives were optimised one at a time while change in other figures of merit was observed. Subsequently, a multi-objective optimisation was done in the search for an optimum compromise between block fuel burn and block emissions. Even though not considered in this research, weighting factors should be 
applied to particular objectives in further studies, emphasizing their contribution to emission levels (i.e. noise and air pollutants) for particular segments of the mission profile. Data related to some air pollutants can be adjusted to contribute more than others for particular segments of the mission profile.

Both single and multi-objective optimisation cases were carried out by means of Simulink ${ }^{\circledR}$ Design Optimization ${ }^{\mathrm{TM}}$ software. A pattern search optimisation method was selected because it is one of the numerical methods Simulink provides for handling multi-objective optimisation problems. Even though there are other solution methods, this algorithm provides satisfactory results by finding a sequence of points that approach an optimal solution.

An initial point is required in order to start the search; such a point is a baseline mission parameter (e.g. forward speed, time in hover or cruise altitude). The algorithm calculates the values of the objective functions until it finds a value within a certain limit given by the user (i.e. upper and lower bounds). That means that the search uses the values that improve the objective function at the next iteration until a minimum is reached. Therefore, when the region where the optimal solution is identified, (i.e. by means of a parameter study) upper and lower bounds on the variables are imposed within the optimisation software; this is accomplished using a Simulink block named Signal Constraint, which can be found in the Simulink Design Optimization Library.

In this case the constraints are defined depending on the range of factors or variables that are close to the optimal solution. The pattern search stops as soon as it finds a smaller value than the current value of the function (e.g. minimum fuel burn or minimum $\mathrm{CO}$ ). In cases where no convergence is reached, the limits of the constraints must be tuned until a result is obtained.

\subsection{Validation and Verification}

Every model contained within the multidisciplinary framework was validated as a standalone. In the case of the helicopter mission performance tool, estimated power and fuel requirements were employed to calculate helicopter capabilities (i.e. rate of climb, service ceiling, range, etc.) as these are the only available data in the open literature that can be used to validate the computational tool ${ }^{(22 ;}$ 23).

The emissions model was verified with hand calculations, which were compared with the experimental data found in FOCA documents ${ }^{(15)}$. On the other hand all models that make part of the rotorcraft mission energy management model were validated with data found in the open literature as well; however, the best engineering judgement was used where no validation data were available.

The design-point of the turboshaft engine performance model was first validated against the type certificate of the engine chosen to run the case study before doing off-design calculations, which are required to execute the helicopter mission performance model. Technical data related to engine performance was obtained from Jane's Aero-Engines and used for validation ${ }^{(21)}$.

\subsection{Setup of Case Study: Baseline Mission Profile, Design Variables and Objectives}

Since this research focuses on civil transport aviation, a passenger transport role was selected to carry out different case studies. For this mission a light single-engine helicopter (i.e. MTOW below 40 $\mathrm{kN}$ ) was selected to run this scenario. Being one the most representative helicopters for passenger transport, a helicopter Bell 206L-4 has been chosen as its size and performance meet the requirements to perform this role. $A$ one-way mission, i.e. from point $A$ to point $B$, has been considered to execute the simulations. 
The segments for this particular operation were arranged so that the following baseline mission is accomplished:

- Start engine at base and await take off clearance.

- Lift into the hovering flight condition in ground effect (IGE) (5 ft) for $5 \mathrm{~min}$, including taxi and checklist procedures with maximum fuel, crew and three passengers.

- Climb $3200 \mathrm{ft}$ above ground level to cruise altitude at $60 \mathrm{kt}$.

- Fly $98 \mathrm{NM}$ to the drop off point at $90 \mathrm{kt}$.

- Descend to the designated landing site at approximately $1800 \mathrm{ft} / \mathrm{min}$.

- Hover IGE (5 ft) at landing site for 5 min including taxi.

- Sit for 5 min with rotors turning on ground.

- Shutdown.

Initially, a design vector, which contains the design variables, was defined in order to form the design space as in equation (2). Five design variables, including speeds, flight altitudes and times, were considered as they can be controlled during the entire mission. At least one variable was used at different flight segments (e.g. hover, climb and cruise).

$$
x=\left[\begin{array}{c}
\mathrm{x}_{1} \\
\mathrm{x}_{2} \\
\mathrm{x}_{3} \\
\mathrm{x}_{4} \\
\mathrm{x}_{5}
\end{array}\right]=\left[\begin{array}{c}
\text { Time } \\
\text { Shaft Horse Power } \\
\text { Skid Height } \\
\text { Forward Speed } \\
\text { Altitude }
\end{array}\right]=\left[\begin{array}{c}
t \\
S H P \\
z \\
V \\
h
\end{array}\right]
$$

The design space exploration requires the designer to make reasonable changes to the design variables in order to attain the desired outcome. For this particular case, the flight envelope and capabilities of the Bell 206L-4 helicopter were borne in mind to guarantee the helicopter can accomplish its designated mission. In summary, the design variables in equation (2) (Fig. 2), which can be controlled during operation as opposed to design variables such as number of blades or fuselage wet area, together with pertinent design ranges, were identified within the design space $e^{(13)}$ before a formal optimisation problem was settled upon results from a parameter study.

\section{Results and Discussion}

\subsection{Single-Variable Parameter Study}

Outcomes are evaluated for hovering flight and ground, during takeoff and landing, and for climb and cruise flight conditions. A parametric study, in which the design variables or factors of the mission change one at a time (i.e. single variable) leaving all others as in the baseline profile, was carried out and appropriate values or so-called levels were designated to each factor. Five general design variables were used for the single variable case.

A range of five levels, carefully selected according to attainable helicopter performance, were allocated to each factor and reasonable level steps were assumed in order to cover most of the design space. Thus, 55 runs were performed for the single-variable parameter study. Only climb and cruise conditions results are presented in this document. Further details related to hovering flight and ground conditions are presented in Linares' research thesis ${ }^{(13)}$. 


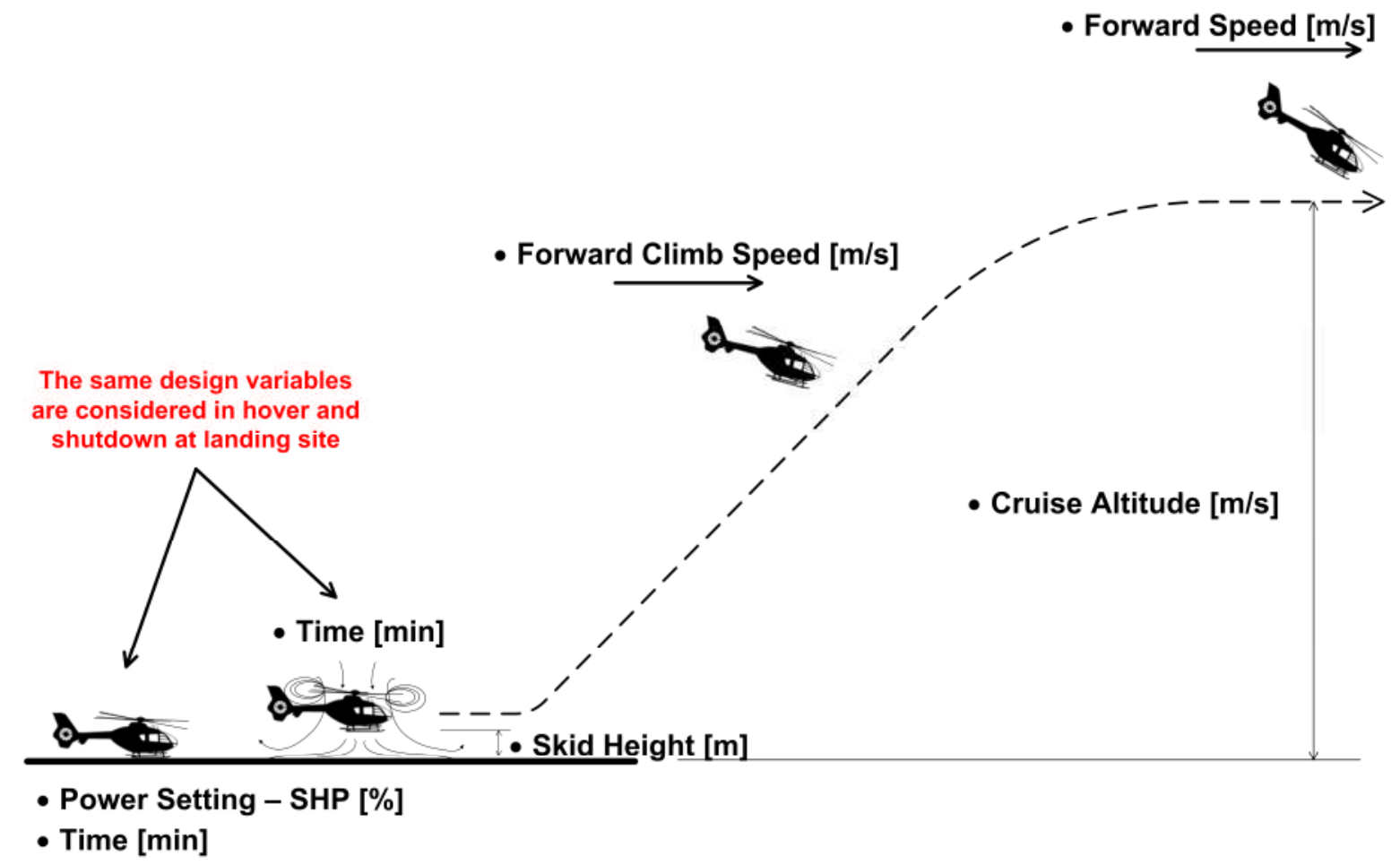

Fig. 2. Design Variables Considered in the Case Study

\subsubsection{Climb to Cruise Altitude}

The climb manoeuvre is performed by adjusting air speed with cyclic control, setting power to obtain climb RPM and increasing collective pitch. As a result, a single factor, namely climb forward speed, was considered for the climb segment of the corporate mission, as this is the only variable that can be controlled to achieve different climb profiles (e.g. steep climb, moderate climb).

Climbs performed close to the best climb angle and best rate of climb (i.e. at low flight speed and best rate of climb speed), are favourable if fuel burn and emissions are to be minimised as it takes less time to climb to the desired cruise altitude, leading to steeper climb profiles. However, steeper profiles will impact the cruise segment, making it longer; as a result, fuel burn and associated emissions increase considerably as the cruise segment becomes predominant in the whole mission (Fig. 3).

Optimal climb speeds on mission profiles for minimum fuel tend to be faster than speeds near the best attainable rate of climb, which is around $55 \mathrm{kt}$ for this particular helicopter. However, during climb, and with forward speed beyond $85 \mathrm{kt}$, parasite drag rises, leading to higher fuel requirements to complete the entire mission. Savings of up to $5 \%$ on fuel burn are possible by managing mission climb profile (Fig. 4).

Since climb is carried out at maximum continuous power, changes in emissions such as $\mathrm{CO}$ and UHC will not depend on SHP. They will be proportional to fuel burn instead, as in the case of $\mathrm{NO}_{\mathrm{x}}, \mathrm{CO}_{2}$, $\mathrm{H}_{2} \mathrm{O}$ and PM (Fig. 5).

\subsubsection{Cruise}

Variation of block fuel with forward speed in cruise indicates that higher speeds are favourable if emissions and fuel burn for the entire mission are to be minimised. Beyond $100 \mathrm{kt}$, block fuel burn increase in cruise is negligible (Fig. 6). In fact, the actual airspeed can practically be faster than the theoretical maximum range speed with an increase of fuel burn due to drag of less than $1 \%$. 


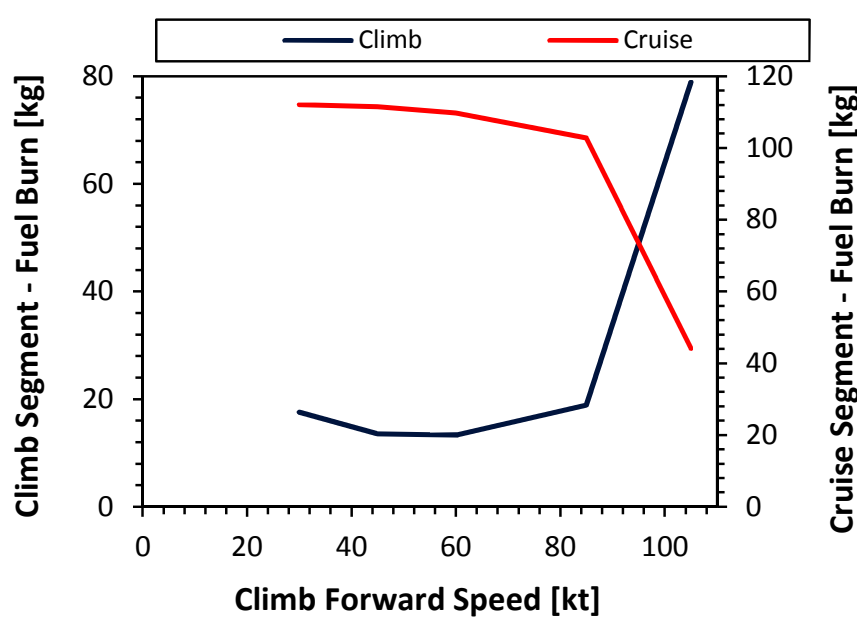

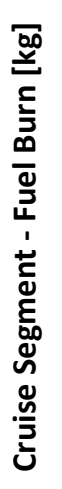

Fig. 3. Variation of Climb and Cruise Fuel Burn with Forward Speed in Climb; Vertical Climb Distance $=1 \mathrm{~km}, \mathrm{ISA}=+20$

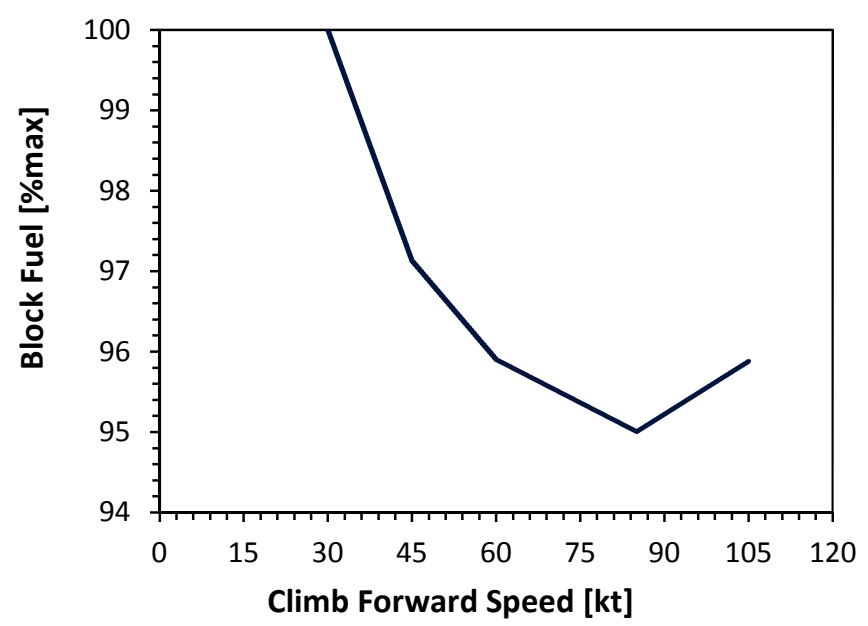

Fig. 4. Variation of Block Fuel with Forward Speed in Climb; Vertical Climb Distance $=1 \mathrm{~km}$, ISA $=+20$

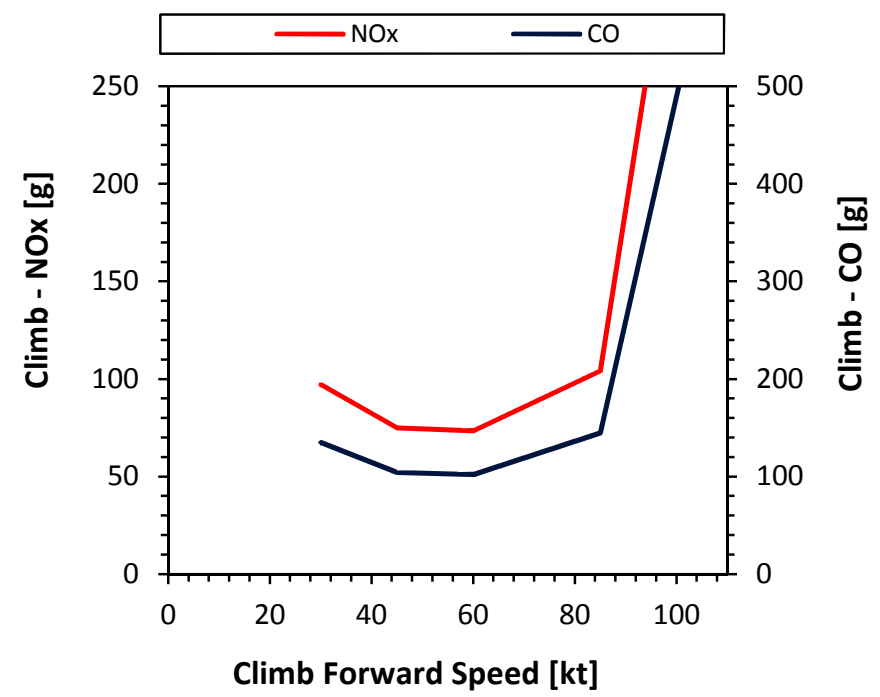

Fig. 5. Variation of Climb $\mathrm{NO}_{x}$ and $\mathrm{CO}$ with Forward Speed in Climb; Vertical Climb Distance $=1 \mathrm{~km}$, $I S A=+20$ 
As a result, high speeds offer a beneficial reduction in block time with a minor range penalty ${ }^{(24)}$. However, beyond speeds near the best rate of climb speed, $\mathrm{NO}_{x}$ and $\mathrm{PM}$ emissions tend to increase about $4-6 \%$ due to an increase in the reaction temperature within the combustion chamber (i.e. driven by Turbine Entry Temperature (TET)), which implies that power requirements to overcome drag have increased and, therefore, fuel is required at higher rates. This results again in a trade-off in which an increase in TET decreases $\mathrm{CO}$ and $\mathrm{UHC}$ emissions while $\mathrm{NO}, \mathrm{PM}, \mathrm{CO}_{2}$ and $\mathrm{H}_{2} \mathrm{O}$ are prone to rise (Fig. 7). The reader is also referred to Linares' research thesis ${ }^{(13)}$ for further analysis on this issue.

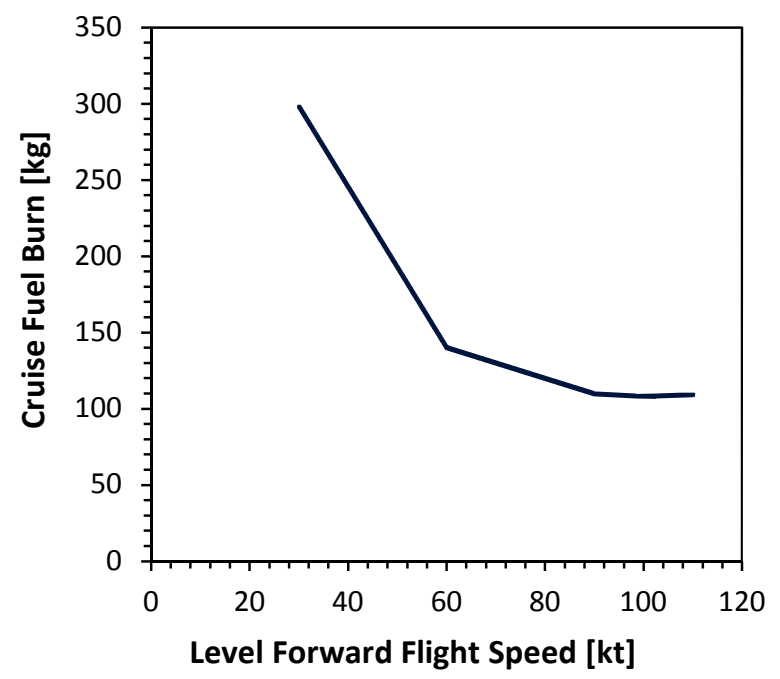

Fig. 6. Variation of Cruise Fuel Burn with Cruise Forward Speed; Cruise Altitude $=1 \mathrm{~km}, I S A=+20$

\subsection{Multi-Variable Parameter Study}

Regarding the multi-variable parametric study, a full-factorial design technique was performed with the design variables from climb and cruise flight conditions (i.e. climb forward speed, cruise forward speed and cruise altitude) since these segments of the mission represent most of the fuel consumed throughout the helicopter operation. Unlike the single variable case, four levels were chosen making reasonable steps.

It is worth mentioning that these levels, as well as parameters of the baseline mission, were established using information from helicopter flight manuals. Experienced pilots were asked about flight data in order to make sure the defined parameters were attainable in real life. A total of 64 runs were performed to get results at every combination of values.

Fuel burn during climb decreases near the speed for best rate of climb at any flight altitude (Fig. 8). However, when considering the factors of the cruise flight segment, ascent at speeds higher than the best rate of climb speed are more favourable to minimise fuel and emissions for the entire mission profile (Fig. 9).

High altitudes, climb forward speeds of 75-80 kt and high cruise speeds (e.g. over speed for best range) are advantageous to minimise block fuel and associated emissions $\left(\mathrm{CO}_{2}\right.$ and $\mathrm{H}_{2} \mathrm{O}$ and $\left.\mathrm{PM}\right)$. This results from complete combustion of fuel and depends on the total amount of carbon in the fuel, rather than on the operating conditions of the helicopter. Even though fuel burn increases by less than $1 \%$ over the best range speed due to a parasite drag increase, by additionally considering climb forward speed, deviation from best range speed in cruise reduces block fuel burn slightly. This may happen because the cruise segment tends to be shorter when climb is carried out at high forward speeds (i.e. at a low climb angle). 


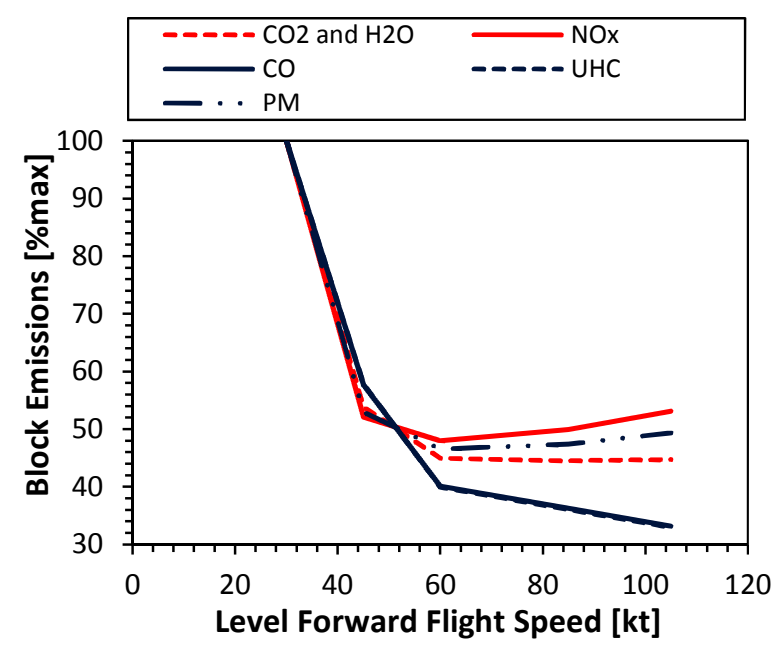

Fig. 7. Variation of Block Emissions with Cruise Forward Speed; Cruise Altitude $=1 \mathrm{~km}, I S A=+20$

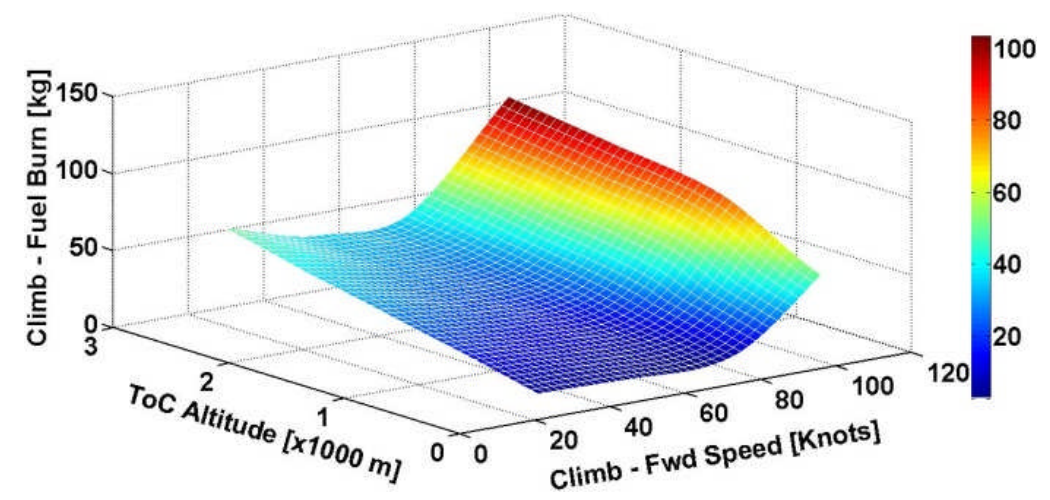

Fig. 8. Variation of Fuel in Climb with Top of Climb Altitude and Forward Speed; ISA=+20

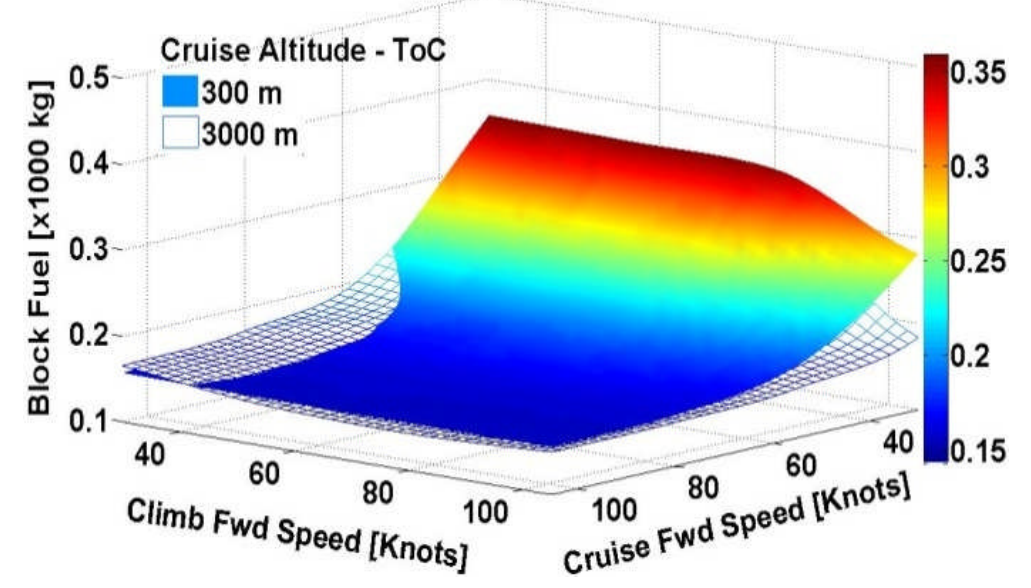

Fig. 9. Variation of Block Fuel with ToC Altitude, and Forward Speed in Climb and Cruise; ISA $=+20$

In contrast, high cruise speeds have a tendency to increase $\mathrm{NO}_{\mathrm{x}}$ emissions due to higher power requirements, which are accompanied by an increase of engine TET, to move the helicopter faster. However, increase in $\mathrm{NO}_{x}$ emissions at cruise speeds over $80 \mathrm{kt}$ may be slight, in the order of $1.5 \%$ (Fig. 10). 
$\mathrm{CO}$ and $\mathrm{UHC}$ emissions, unlike $\mathrm{CO}_{2}$ and $\mathrm{NO}_{x}$ pollutants, decrease as cruise and climb forward speeds increase (Fig. 11). This confirms again the existing trade-off among these air pollutants as low gas temperatures, driven by engine TET, increase $\mathrm{CO}$ and UHC emissions, making operating conditions more favourable for $\mathrm{NO}_{x}$ reduction.

\subsection{Single-Objective Optimisation}

Optimisation for single objectives was carried out by means of Simulink ${ }^{\circledR}$ Design Optimization ${ }^{\mathrm{TM}}$ software. A pattern search optimisation method to minimise fuel burn, emissions and time was selected. Variation of other objectives was observed while varying cruise and climb forward speeds, whose initial values were identified in the previous parametric study. The remaining figures of merit were assessed while objectives were optimised one at a time. The reader is referred to Linares' research thesis ${ }^{(13)}$ for further details on minimum $\mathrm{CO}, \mathrm{UHC}$ and PM emissions.

\subsubsection{Minimum Block Fuel and Associated Emissions $\left(\mathrm{CO}_{2}\right.$ and $\left.\mathrm{H}_{2} \mathrm{O}\right)$}

Optimising for minimum fuel burn also implies reductions in $\mathrm{CO}_{2}$ and $\mathrm{H}_{2} \mathrm{O}$ emissions since these are inevitable end products of the fuel-burning process. A reduction of $3.35 \%$ in block fuel resulted in a slight increase of about $2 \%$ in $\mathrm{NO}_{x}$ emissions while $\mathrm{CO}$ and $\mathrm{UHC}$ emissions decreased about $15 \%$ in relation to the non-optimised baseline mission profile (Fig. 12).
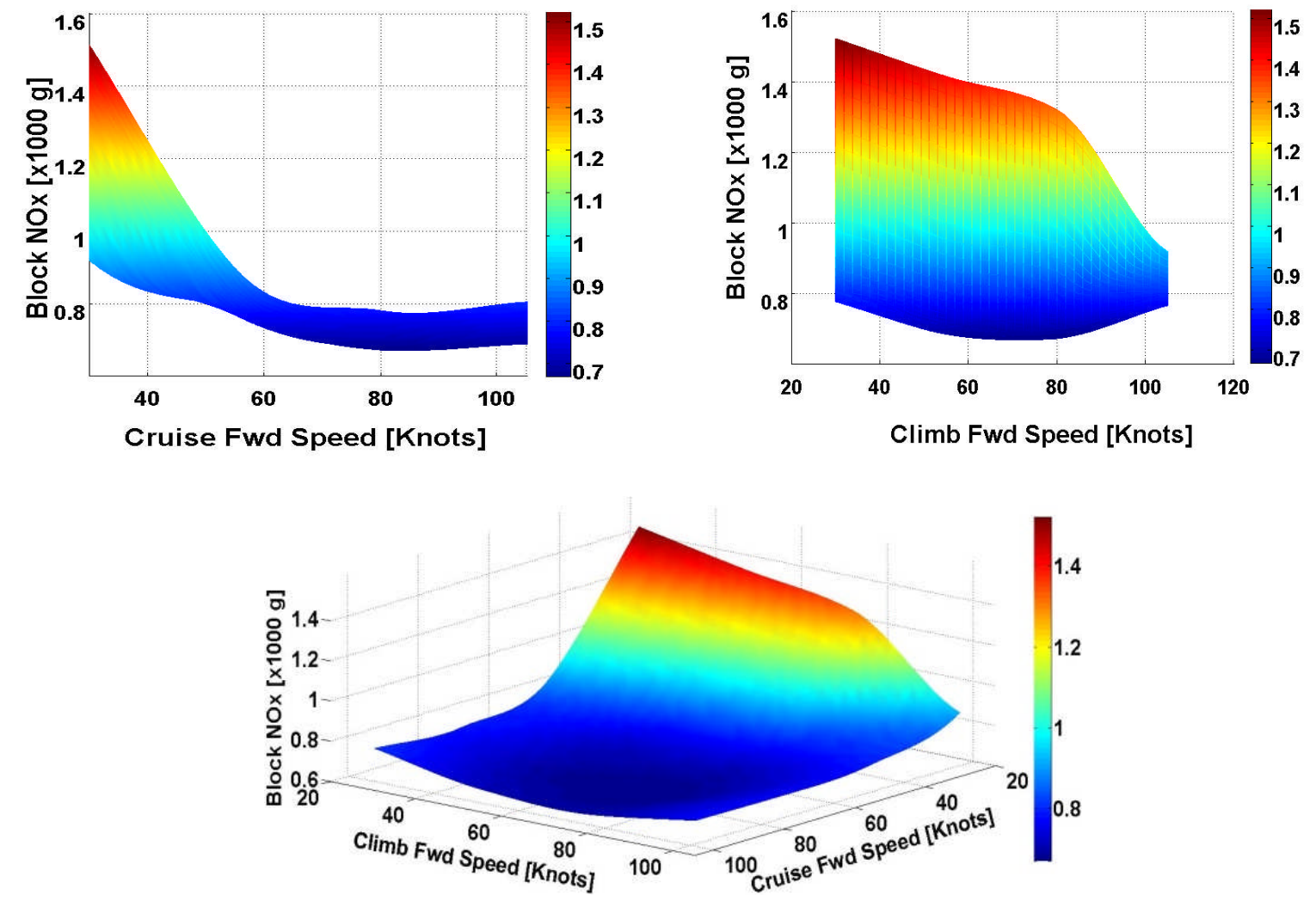

Fig. 10. Variation of Block $\mathrm{NO}_{x}$ with Forward Speed in Climb and Cruise; Flight Altitude $=3000 \mathrm{~m}$, ISA $=+20$ 

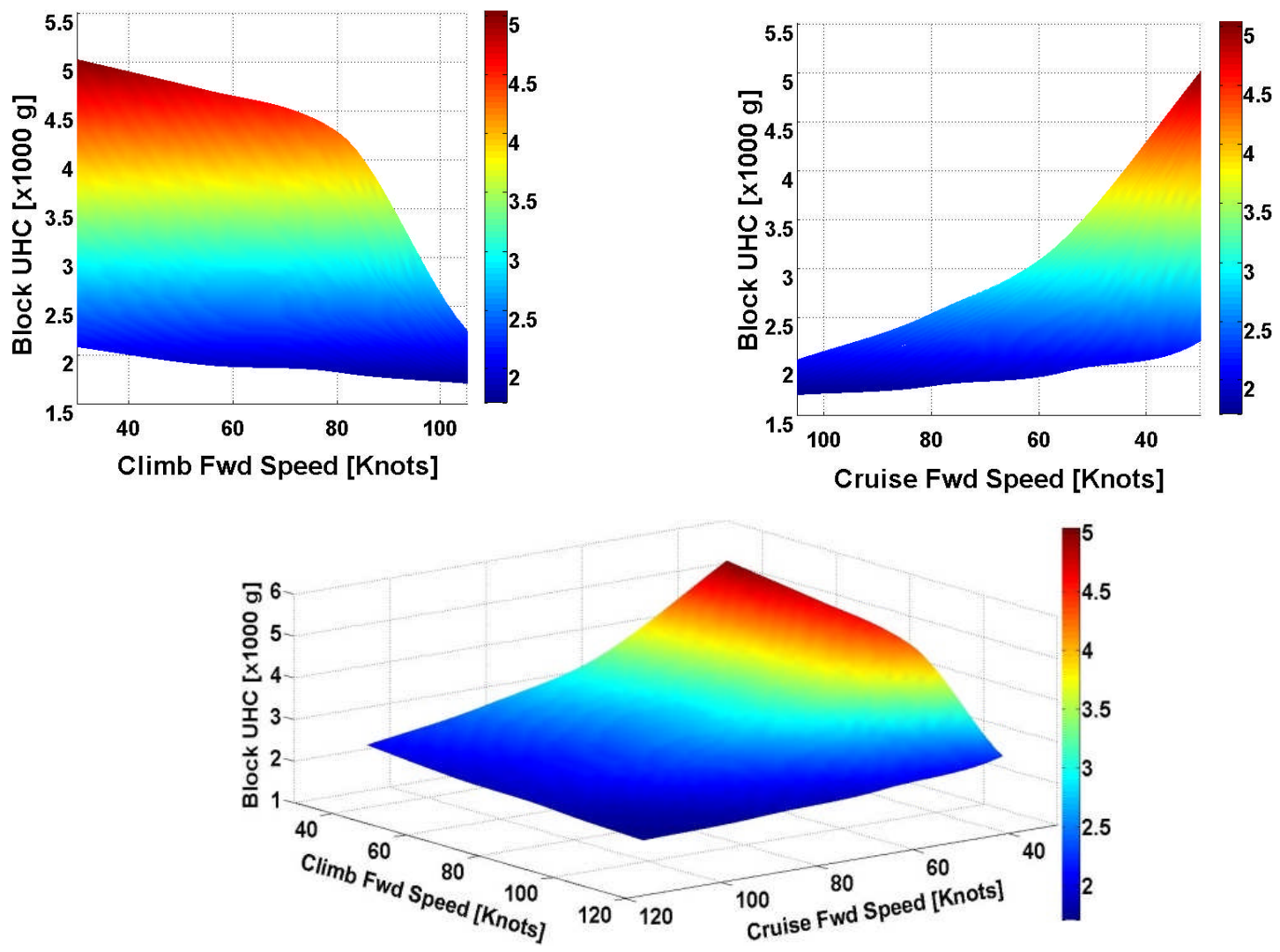

Fig. 11. Variation of Block UHC with Forward Speed in Climb and Cruise; Flight Altitude $=3000 \mathrm{~m}$, ISA $=+20$

\subsubsection{Minimum $\mathrm{NO}_{x}$}

A reduction of up to $1.5 \%$ of $\mathrm{NO}_{\mathrm{x}}$ emissions can be achieved compared to the baseline mission profile. This minor $\mathrm{NO}_{x}$ reduction, however, causes $\mathrm{CO}$ and $\mathrm{UHC}$ emissions to rise slightly. Looking at other figures of merit, fuel burn and its associated air pollutants decrease no more than $1.1 \%$ (Fig. 13). Even though it seems to be an attractive solution, it would be interesting to go for a multiobjective optimisation, taking into account all the objectives, to minimise $\mathrm{CO}$ and $\mathrm{UHC}$ emissions, and fuel burn as much as possible.

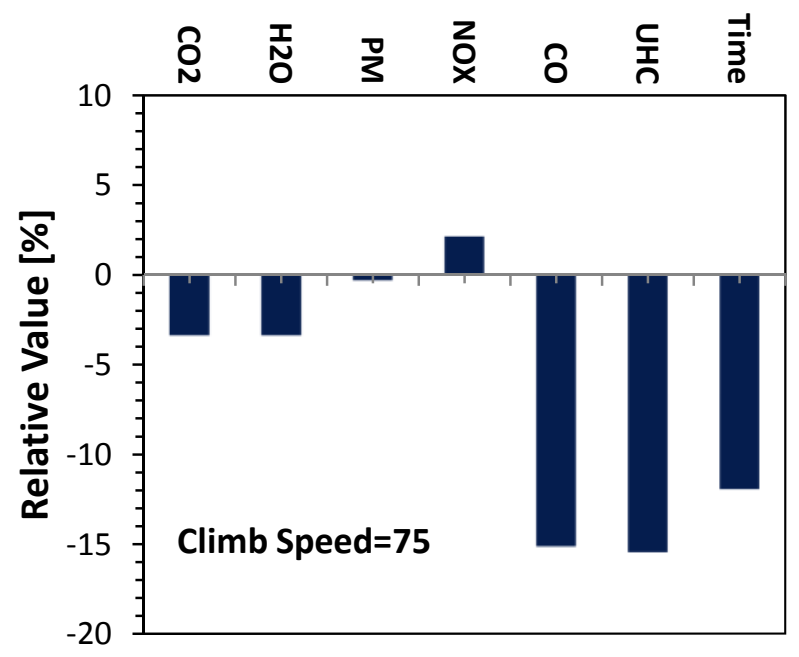

Figure of Merit

Fig. 12. Relative Values of Emissions and Time for Minimum Fuel Burn 


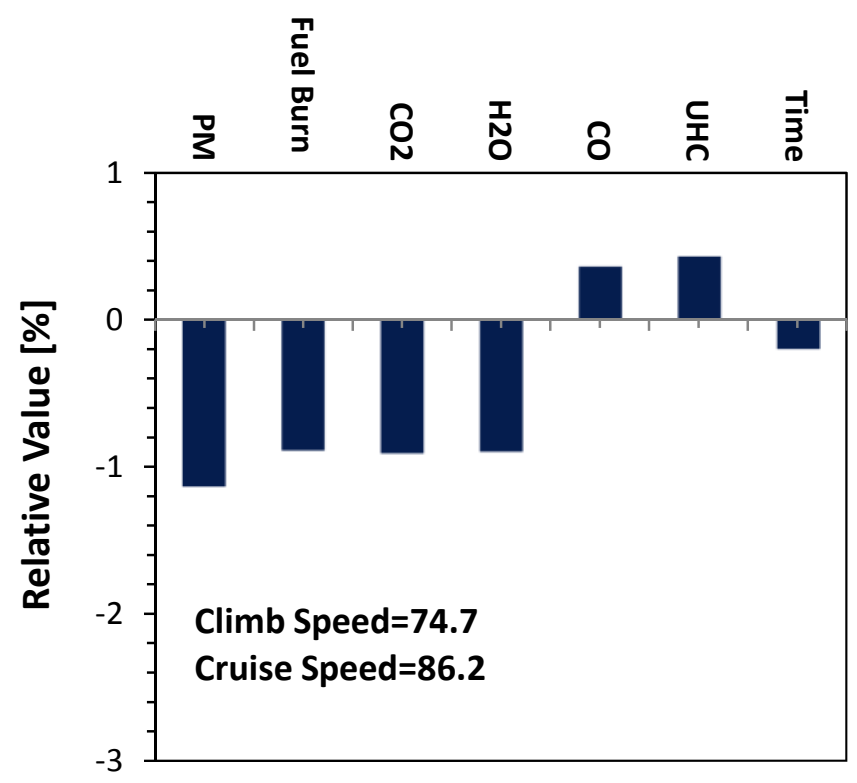

Figure of Merit

Fig. 13. Relative Values of Fuel Burn, Emissions and Time for Minimum $\mathrm{NO}_{x}$ Emissions

\subsection{Multi-Objective Optimisation}

A Multi-objective Optimisation was performed using the same pattern search optimisation method used for single-objective optimisation in order to find the optimum compromise between the following objectives: fuel burn, NOX and CO emissions. During the multi-objective optimisation, these objectives are assumed to have the same contribution to air pollution during the climb and cruise segments, this means that there is no emphasis on a particular objective (i.e. no weight factors are applied).

The trade-off in the design space shows that as the number of objectives increase, the tendency is to aim for lower climb and cruise speeds (Fig. 14). As shown in Fig. 15, high cruise altitudes are favourable for minimum block fuel burn and for minimum air pollutant emissions (i.e. as long as cruise and climb forward speeds remain beyond $70 \mathrm{kt}$ ); therefore, the design space was explored at a constant cruise altitude of $3000 \mathrm{~m}$, which is usually the maximum cruise altitude for this helicopter type. The mission was, therefore, explored to find the range of speeds in which minimum fuel burn (which implies minimum $\mathrm{CO}_{2}$ and $\mathrm{H}_{2} \mathrm{O}$ ), minimum $\mathrm{NO}_{x}$, and minimum $\mathrm{CO}$ and $\mathrm{UHC}$ emissions are found. A Pareto front would provide a good representation of the tradeoff between fuel burn and emissions; however, a Pareto analysis will be a subject for future work.

The optimised design prompts to a reduction of $2 \%$ in block fuel and up to $4.7 \%$ decrease of time, and $\mathrm{CO}$ and UHC emissions, all this, followed by a negligible increase of $0.11 \%$ in $\mathrm{NO}_{\mathrm{x}}$ emissions. Changes in particle matters were not relevant during the entire optimisation process (Fig. 16).

The resulting forward speeds that provide the best compromise among all the objectives of this optimisation are compared with the baseline mission profile. Climb forward speed for the baseline mission profile was defined as $60 \mathrm{kt}$, whereas the optimisation process suggests a speed of $90.2 \mathrm{kt}$ for climbing. For the cruise forward speed variable, significant changes were not evident, as the difference between the baseline profile and the optimised profile is only $3 \mathrm{kt}$, giving forward speeds in cruise of $90 \mathrm{kt}$ and $87 \mathrm{kt}$, respectively. 


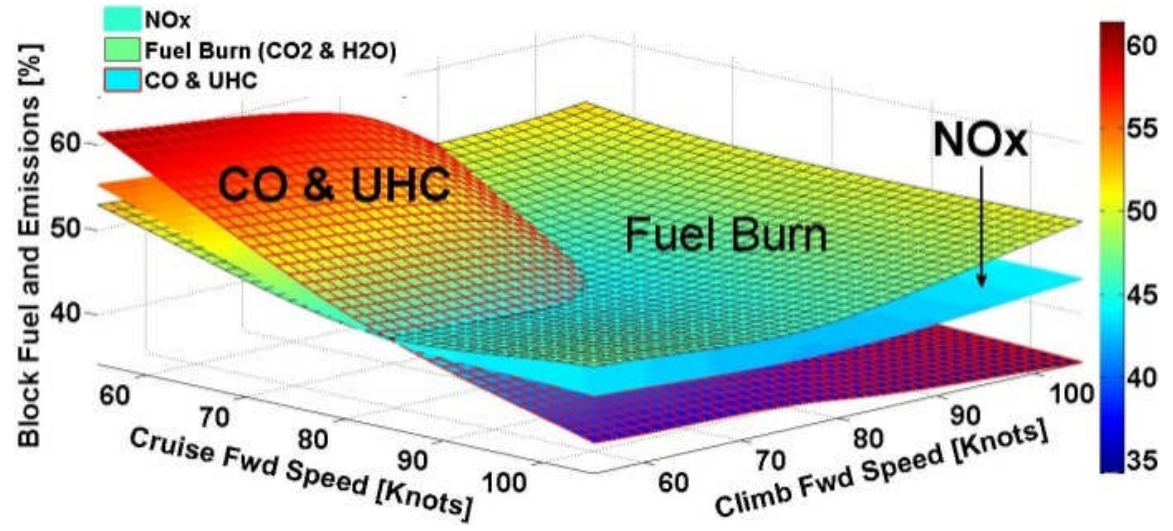

Fig. 14. Variation of Block Fuel and Emissions with Forward Speed in Climb and Cruise; ISA $=+20$

For this particular case, forward climb speeds over the speed for best rate of climb are favourable to reduce helicopter emissions and fuel burn during the entire mission, even though emissions and fuel burn increase during the climb segment.

Reductions in block fuel may not be significant for a single helicopter flying any particular mission. However, potential of mission profile management has proved to be favourable to minimise fuel burn for a particular mission profile because If a $2 \%$ reduction can be achieved for a single helicopter performing one rotation, attractive fuel savings can be attained for an entire fleet of helicopters flying more than one rotation per day. However, a better compromise may be found for $\mathrm{NO}_{\mathrm{x}}$ emissions even if they only account for an additional $0.1 \%$ per rotation.
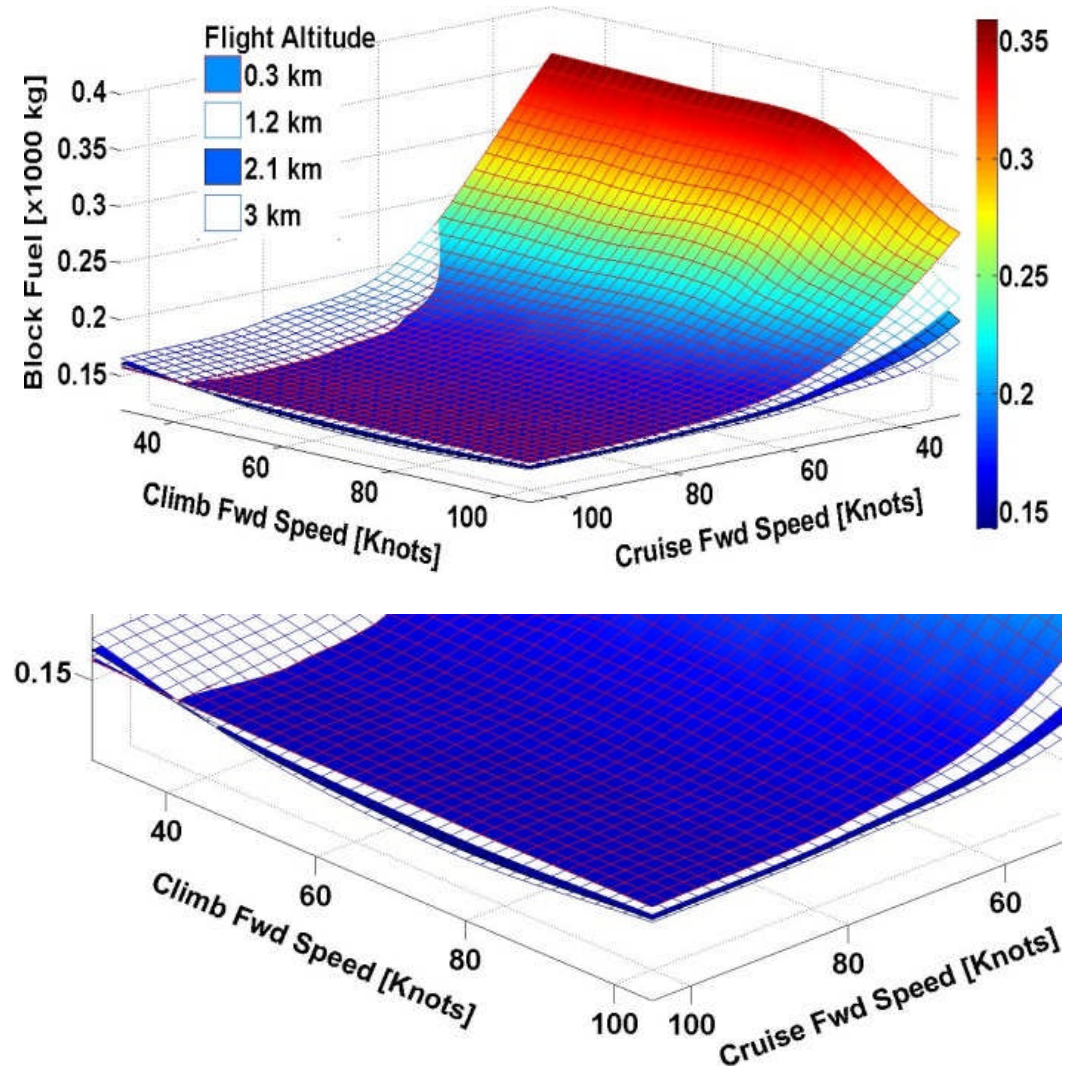

Fig. 15. Block Fuel Burn as a Function of Cruise Altitude and Flight Speed in Climb and Cruise 


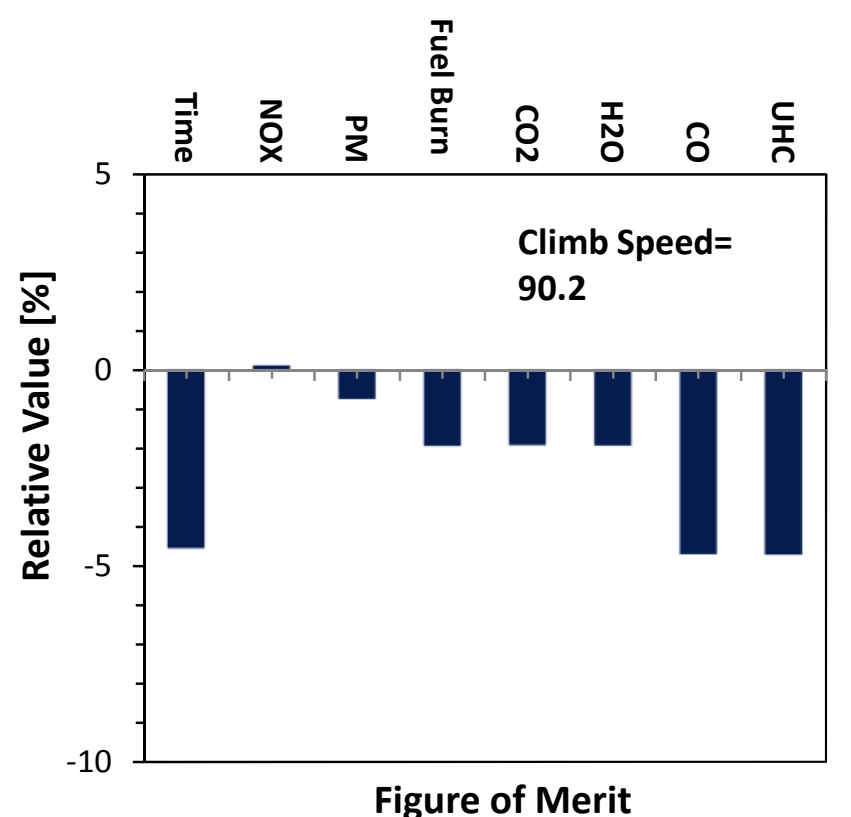

Fig. 16. Multi-Objective Optimisation for Fuel Burn, Emissions and Time

It is worth noting that this $2 \%$ reduction was achieved only by optimising for cruise and climb segments (i.e. hover and ground remained as in the baseline profile). As observed in the singlevariable parameter study, additional savings of up to $3 \%$ are possible when managing times in hover and ground during takeoff and landing phases.

\section{Conclusion}

A multidisciplinary computational tool for the assessment of the environmental footprint of helicopters under given flight conditions has been developed. The capabilities of the multidisciplinary assessment framework were tested for a particular mission profile, proving its capabilities of generating outputs at conceptual level for subsequent optimisation. Outcomes provided by the multidisciplinary framework were generated to explore the design space of helicopter operations at mission level. A parametric study was the first step into the exploration where results showed the effect of changing aircraft flight parameters on emissions and fuel burn during a helicopter corporate mission.

The parametric study gave a general idea of the results reaction to every combination of controllable variables (i.e. Flight Parameters) within the design space. Additionally, the parameter study provided a wide overview of key design variables and its appropriate design ranges, being very useful before setting up the formal optimisation study for minimum fuel burn and emissions. Mission flight parameters, optimised for minimum block fuel burn (i.e. single-objective optimisation) suggest that reductions of up to $3.35 \%$ are attainable at the expense of a $2 \%$ increase of $\mathrm{NO}_{x}$ emissions produced during the entire flight. High cruise forward speeds were demonstrated to be favourable, since increase in fuel burn is less than $1 \%$ over the speed for maximum range, even if fuel flow increases due to airframe drag.

Results suggest that mission profile management has a benefit to reduce environmental impact due to air pollutants produced by helicopter engines. Even though reductions of $2 \%$ in block fuel burn and up to $5 \%$ in block time, and $\mathrm{CO}$ and UHC emissions are possible optimising only for cruise and climb segments for a single helicopter, striking fuel savings can be achieved for an entire fleet of helicopters flying more than one rotation per day. It is envisaged that improvements to this methodology, including noise and wind models, as well as breakthrough technologies for secondary power systems, will prove the capabilities of this tool for future success of mission profile management. Future work includes the development of a dynamic model which will fully use the capabilities of Simulink. 


\section{Acknowledgements}

The authors would like to thank the Clean Sky Joint Technology Initiative for sponsoring this research project for a greener and more sustainable aviation. Thanks to Henry Porras, MSc student from Cranfield University, for developing the emissions model. The authors would also like to express acknowledgments to Nadège Hugon, colleague from the MSc in Aerospace Vehicle Design, for her assistance in simulating the engine performance model. Finally, thanks to all Cranfield University colleagues, Rolando Vega, Jhonn Ruge and Ahmed Shinkafi, for providing the research team with data related to the RMEM computational models involved in this research.

\section{References}

1. Goulos, I., Mohseni, M., Pachidis, V., D'Ippolito, R. and Stevens J. (2010), "Simulation Framework Development for Helicopter Mission Analysis", in ASME Conference Proceedings (ed.), ASME Turbo Expo 2010: Power for Land, Sea, and Air (GT2010), Vol. 3, June 14-18, 2010, Glasgow, UK, ASME, United Kingdom.

2. Erzberger, H., and Slater, G. (1982), Optimal Short-Range Trajectories for Helicopters, 84303, NASA, Moffett Field, CA.

3. Wayne, J. (2010), "NDARC-NASA Design and Analysis of Rotorcraft Theoretical Basis and Architecture", American Helicopter Society Aeromechanics Specialists' Conference, January 2022, San Francisco, CA., NASA, USA.

4. Davis, S., Rosenstein, H., Stanzione, K., and Wisniewski, J. (1979), HESCOMP. The Helicopter Sizing and Performance Computer Program. User's manual, revision 2, NASA-CR-168697, CASI, USA.

5. Nijland, T., Atyeo, S., and Sinha, A. (2004), "A Simulation Model For Flight Performance Analysis Of Helicopter Mid-Life Upgrade Designs", 30th European Rotorcraft Forum, 14-16 Sept. 2004, Marseille; France, National Aerospace Laboratory NLR, Amsterdam.

6. Palmer. (Cranfield University), (1999), The TURBOMATCH Scheme for Aero/Industrial Gas Turbine Engine Design Point/Off Design Performance Calculation (unpublished User's Guide), United Kingdom.

7. Leishman, J. (2006), Principles of Helicopter Aerodynamics, 2nd ed, Cambridge University Press, Cambridge.

8. Army Materiel Command, Alexandria, VA (1974), Engineering design handbook. Helicopter engineering, part 1: Preliminary design (for VFR operation), AD-A002007; AMCP-706-201-PT-1; Pagination 876P.

9. Padfield, G. D. (1996), Helicopter Flight Dynamics: The Theory and Application of Flying Qualities and Simulation Modelling, 1st ed, Blackwell Science, Cambridge, UK.

10. Bramwell, A. R. S., Done, G. and Balmford, D. (2001), Bramwell's Helicopter Dynamics, 2nd ed, Butterworth-Heinemann, Oxford, UK.

11. Filippone, A. (2006), Flight Performance of Fixed and Rotary Wing Aircraft, 1st ed, Elsevier, Oxford.

12. Stepniewski, W. Z., and Keys, C. N. (1984), Rotary-Wing Aerodynamics, 2nd ed, Dover, London.

13. Linares, C. (2011), Environmental Impact Assessment of the Operation of Conventional Helicopters at Mission Level (MSc by Research thesis), Cranfield University, United Kingdom. 
14. Allaire, D. (2006), A Physics-Based Emissions Model for Aircraft Gas Turbine Combustors (Master of Science in Aerospace Engineering thesis), Massachusetts Institute of Technology, United States of America.

15. Rindlisbacher, T. (2009), Guidance on the Determination of Helicopter Emissions, , Federal Office of Civil Aviation, FOCA, Switzerland.

16. IPCC (1999), IPCC Special Report: Aviation and the Global Atmosphere, , Cambridge University Press, United Kingdom.

17. Coutinho, A. (2008), Performance and Emission Optimisation of Novel Aero-Engine Concepts (MSc Thesis), Cranfield University, United Kingdom.

18. Messinger, B. L. (1953), "Equilibrium Temperature of an Unheated Icing Surface as a Function of Air Speed", Journal of the Aeronautical Sciences, vol. 20, no. 1, pp. 29-42.

19. Vega, R. (2011), Analysis of an Electric Environmental Control System to Reduce the Energy Consumption of Fixed-Wing Aircraft and Rotary-Wing Aircraft (MSc by Research thesis), Cranfield University, United Kingdom.

20. Newman, S.J., ( 2011), Methods of Calculating Helicopter Power, Fuel Consumption and Mission Performance., University of Southampton, Southampton, GB.

21. Hugon, N. (2011), Assessment of Novel Propulsion System Configurations for Rotorcraft: Individual Research Project (MSc in Aerospace Vehicle Design thesis), Cranfield University, United Kingdom.

22. Defense \& Security Intelligence \& Analysis: IHS Jane's (2011), Jane's All the World's Aircraft, available at: http://jawa.janes.com/public/jawa/index.shtml (accessed June/02).

23. Bell Helicopter: a Textron Company, ( 2010), Bell 206L4 Product Specifications, Bell Helicopters, Canada.

24. Watkinson, J. (2004), The Art of the Helicopter, 1st ed., Elsevier, Oxford, UK. 